\title{
EVASÃO NA EDUCAÇ̃̃O SUPERIOR: LICENCIATURAS NA UNIVERSIDADE DO ESTADO DE MATO GROSSO - UNEMAT CAMPUS DE CÁCERES/MT
}

\author{
Evasion in Higher Education: degrees at the University of the state of Mato Grosso - \\ UNEMAT campus of Cáceres/MT
}

\section{Abandono de la Educación Superior: licenciatura en la Universidad del Estado de Mato Grosso - UNEMAT campus Cáceres/MT}

\author{
Suzely Paesano Neves \\ Heloisa Salles Gentil ${ }^{* *}$ \\ Fernando Cezar Vieira Malange *** $^{*}$
}

\begin{abstract}
Resumo
O presente artigo problematiza questões relativas à permanência e não permanência na Educação Superior, tendo em vista que a evasão tem se apresentado como um dos maiores problemas das Instituições de Ensino Superior - IES na atualidade. O objetivo é analisar a evasão na interface com a movimentação acadêmica durante o período mínimo previsto para integralização dos cursos de licenciatura na UNEMAT, campus de Cáceres. Para tanto, caracteriza-se a universidade lócus desta pesquisa, especificamente em relação aos cursos de licenciatura, apresentando seu histórico no contexto de expansão das IES no interior do país; expõe-se os dados coletados sobre os cursos em foco, concomitantemente discutindo, a partir de pesquisadores da área como Silva e Veloso (2012); Veloso e Nogueira (2014); Lima, Malange e Barbosa (2018); Maciel, Lima e Gimenes (2016); conceitos de acesso e permanência, essenciais para a compreensão do fenômeno pesquisado. Os resultados são provenientes da análise de documentos e estudo de referenciais e indicam a necessidade de aprofundamento de estudos sobre o mesmo tema e a necessidade de políticas de permanência mais expressivas, que compreendam o acompanhamento do fluxo acadêmico como possibilidade de maior êxito em seus fins.
\end{abstract}

PALAVRAS CHAVES: Evasão. Permanência. Fluxo acadêmico

\begin{abstract}
This article problematizes issues related to permanence and non-permanence in higher education, taking into account that dropping out has been presented as one of the biggest problems of the Higher Education Institutions - IES nowadays. The objective is to analyze the dropout in its interaction with academic mobility during the minimum period planned for the completion of the degree courses at the UNEMAT, campus of Cáceres. For this purpose, the university is characterized as locus of this research, specifically in relation to the degree-level courses, presenting its historical record in the context of expansion of IES in the interior of the country; the

\footnotetext{
*Mestre em Educação. Profissional Técnico da Educação Superior da Universidade do Estado de Mato Grosso - UNEMAT. E-mail: suzely@ unemat.br. Orcid: https://orcid.org/0000-0003-0469-3871

*** Doutora em Educação. Docente do Programa de Pós Graduação em Educação - Campus Cáceres da Universidade do Estado de Mato Grosso-UNEMAT. E-mail: logentil@ gmail.com. Orcid: https://orcid.org/0000-0001-8299-208X

* Doutor em Eng. Elétrica. Docente da Faculdade de Ciências Exatas e Tecnológicas e do Programa de Pós Graduação em Educação - Campus Cáceres da Universidade do Estado de Mato Grosso-UNEMAT. E-mail: fmalange@unemat.br. Orcid: https://orcid.org/0000-0002-2210-8245
} 
data collected on the courses in question are exposed, discussing simultaneously, based on researchers from the area such as Silva and Veloso (2012), Veloso and Nogueira (2014); Lima, Malange and Barbosa (2018); Maciel, Lima and Gimenes (2016), the concepts of access and permanence, essential for the understanding of the investigated phenomenon. The results come from the analysis of documents and the study of references that indicate the need to delve into studies on the same subject as well as to implement more expressive permanence policies, which include the accompaniment of the academic flow as a possibility of greater success for its goals.

KEYWORDS: Dropping out. Permanence. Academic flow

\section{Resumen}

El presente artículo problematiza cuestiones relativas a la permanencia y no permanencia en la educación superior, teniendo en cuenta que la deserción se ha presentado como uno de los mayores problemas de las Instituciones de Educación Superior - IES en la actualidad. El objetivo es analizar La deserciónen su interacción com la movilidad académica durante el periodo mínimo previsto para La finalización de los cursos de licenciatura en la UNEMAT, campus de Cáceres. Para tal fin, se caracteriza a la universidad locus de esta investigación, específicamente en relación a los cursos de licenciatura, presentando su registro histórico en el contexto de expansión de las IES en el interior del país; se exponenlos datos recogidos sobre los cursos em cuestión, discutiendo simultáneamente, a partir de investigadores del área como Silva y Veloso (2012), Veloso y Nogueira (2014); Lima, Malange y Barbosa (2018); Maciel, Lima yGimenes (2016), conceptos de acceso y permanencia, esenciales para la comprensión del fenómeno investigado. Los resultados provienen del análisis de documentos y estudio de referenciales e indican la necesidad de ahondaren estudios sobre el mismo tema y de implementar políticas de permanencia más expresivas, que comprendan el acompañamiento del flujo académico como posibilidad de mayor éxito para sus metas.

PALABRAS CLAVE: Deserción. Permanencia. Flujo académico

\section{INTRODUÇÃO}

A proposta de democratização do acesso à Educação Superior vem sendo discutida, elaborada e implementada no Brasil desde a década de 1990, mais especificamente, após a promulgação da Lei de Diretrizes e Base da Educação Nacional - LDB 9394/1996 que, entre outras questões, definiu a obrigação da União de elaborar um Plano Nacional de Educação - PNE. Neste são definidas metas e estratégias para se atingir os objetivos da educação, em consenso com processos democráticos e participativos entre a sociedade civil e o governo. Dados os impasses e as dificuldades dos processos, de lá para cá, aprovou-se dois planos, estando vigente até 2024 o aprovado pela Lei 13.005/2014.

No primeiro PNE a meta era prover, até o final da década, a oferta de Educação Superior para, pelo menos, $30 \%$ da faixa etária de 18 a 24 anos. A proposta inicial do PNE 2011-2020, em sua meta 12, foi de "elevar a taxa bruta de matrícula na Educação Superior para $50 \%$ e a taxa líquida para $33 \%$ da população de 18 a 24 anos, assegurando a qualidade da oferta" (BRASIL, 2010, p.77).

De acordo com a análise de Vasconcelos (2016) sobre os dados do Instituto Brasileiro de Geografia e Estatística - IBGE de 2010, quanto ao ensino superior, era possível observar

[...] que somente 19,0\% (14,5\% em curso e 4,2\% concluído) dos jovens entre 18 e 24 anos haviam alcançado esse nível de ensino. Esse percentual, uma 
aproximação da taxa líquida de matrícula no ensino superior, é muito inferior aos 33,0\% estabelecido pelo PNE 2011-2020 (VASCONCELOS, 2016, p.127).

Mas a aprovação do Plano se deu três anos depois da elaboração inicial, tendo sido esse um dos impasses relacionados à destinação de recursos para a educação (meta 20). Em 2014 foi então aprovada a Lei 13.005/2014 (PNE 2014-2024) cuja meta 12 ficou assim estabelecida:

Elevar a taxa bruta de matrícula na Educação Superior para 50\% (cinquenta por cento) e a taxa líquida para 33\% (trinta e três por cento) da população de 18 (dezoito) a 24 (vinte e quatro) anos, assegurada a qualidade da oferta e expansão para, pelo menos, $40 \%$ (quarenta por cento) das novas matrículas, no segmento público (BRASIL, 2014)

De acordo com o Ministério de Educação - MEC

[...] as matrículas na Educação Superior brasileira cresceram de 3,9 milhões em 2003 para 7,3 milhões em 2013 - o equivalente a $86 \%$. O contingente de estudantes matriculados na Educação Superior em 2013 representa uma taxa de escolarização bruta de $29 \%$ e taxa de escolarização líquida de $18 \%$ (BRASIL, 2014, p. 26)

No que diz respeito à Educação Superior é possível afirmar que, ações e programas vêm sendo executados em função da democratização do acesso (ainda que se possa discutir as concepções de democratização e de acesso) ao referido nível de ensino. Dentre elas, podemos citar o Fundo de Financiamento Estudantil - FIES em 1999, e o Programa "Universidade para Todos" - PROUNI em 2005, ambos criados para estimular o acesso à Educação Superior na rede privada; a instituição do Programa Expansão das Universidades Federais, em 2003, e o Programa de Apoio a Planos de Reestruturação e Expansão das Universidades Federais - REUNI, uma das ações integrantes do Plano de Desenvolvimento da Educação - PDE 2001-2010, focados na expansão das universidades federais, além da criação de novas Instituições Federais de Ensino Superior - IFES, novos campi e consolidação das instituições já existentes.

Gráfico 1 - Evolução da matrícula na educação superior de graduação por categoria administrativa/Brasil 2008-2018.

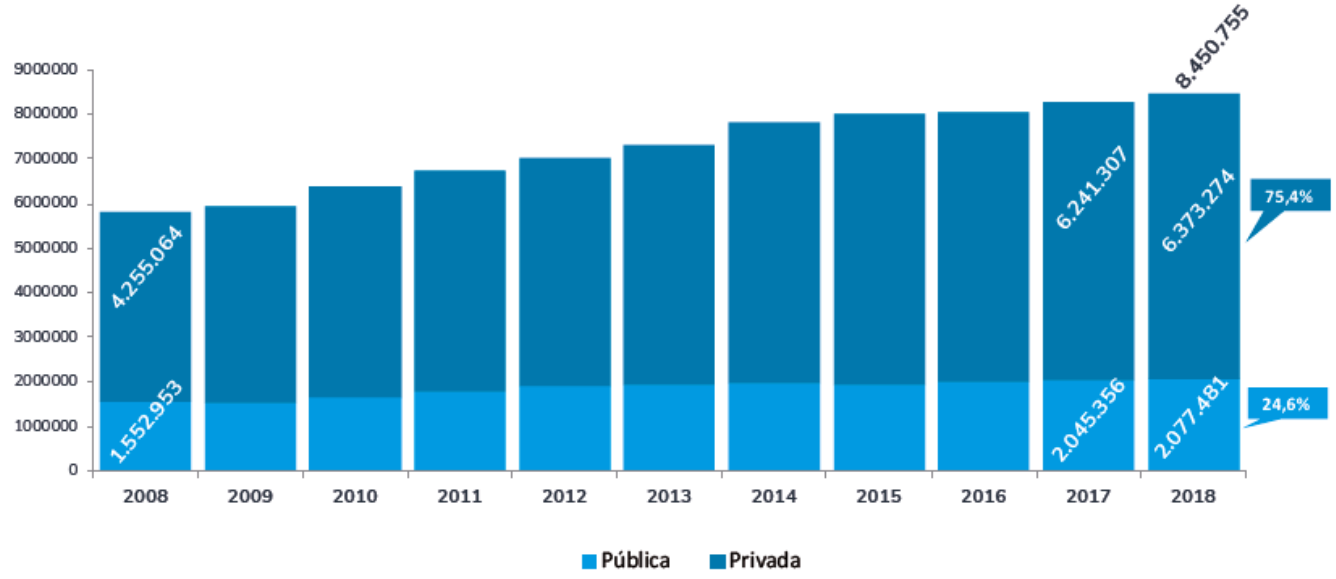

Fonte: Censo da Educação Superior 2018: Notas Estatísticas. Brasília, 2019. 
Com a influência deste conjunto de programas, o percentual de alunos matriculados nos cursos presenciais de graduação elevou-se de modo expressivo, com mais de 6 milhões de alunos, a rede privada tem três em cada quatro alunos de graduação. Em 2017, a matrícula na rede pública cresceu $2,8 \%$ e a matrícula na rede privada volta a crescer $(3,0 \%)$ após a queda registrada em 2016. Comparando os dados dos anos de 2008 a 2018, observase um aumento no número de matrículas de $49,8 \%$ na rede privada e de $33,8 \%$ na rede pública (Gráfico 1).

Contudo, com a expansão surge também a questão da evasão dos estudantes dos cursos de graduação, tornando-se um desafio para todas as IES, sejam elas públicas ou privadas.

Frente a essa problemática, este artigo busca analisar a evasão de forma mais focalizada: na interface com a movimentação acadêmica durante o período mínimo previsto para integralização dos cursos de licenciatura na UNEMAT, campus de Cáceres. Devido a IES se fazer presente em praticamente todo o Estado de Mato Grosso e ofertar mais de cem cursos, entre licenciaturas e bacharelados, utilizamos, para delimitar o campo e período de pesquisa, os seguintes critérios:

1. A filosofia inicial da IES foi capacitar professores para atuar nas escolas do município de Cáceres, assim definimos como foco deste estudo os cursos de licenciatura;

2. A escolha do lócus da pesquisa foi determinada pela quantidade de oferta de cursos de licenciatura, tendo sido constatado que o Campus Universitário de Cáceres oferta maior número desses cursos, e

3. Consideramos a possibilidade de obtenção de dados dos estudantes desde o ingresso até a conclusão dos cursos, assim, optamos pelos ingressantes nos cursos de licenciatura do Campus UNEMAT/Cáceres em 2014/1 com prerrogativa de conclusão dentro do prazo mínimo de integralização previsto nos Projetos Pedagógicos de Cursos PPC, em 2017/2.

Este texto problematiza questões relativas ao acesso e permanência na Educação Superior, caracteriza a universidade lócus desta pesquisa, especificamente em relação aos cursos de licenciatura, apresentando seu histórico no contexto de expansão das IES no interior do país, expõe os dados coletados sobre os cursos em foco, concomitantemente discutindo, a partir de pesquisadores da área, conceitos de acesso, permanência e evasão, essenciais para a compreensão do fenômeno pesquisado.

\section{Expansão e acesso à Educação Superior}

A democratização do acesso se consolida entre os anos de 2003 a 2011, a partir de programas e projetos do governo federal, incluindo Políticas de Ação Afirmativa, que visam oferecer igualdade de condições de acesso à classe menos favorecida histórica e economicamente. Nesta perspectiva foi instituído o Programa Universidade para Todos PROUNI (Lei 11.096/2005), que tem "como finalidade a concessão de bolsas de estudo integrais e parciais, em cursos de graduação e sequências de formação específica, em instituições de ensino superior privadas", podendo os bolsas ser concedidas através de "instituições privadas de ensino superior com fim ou sem fim lucrativo, para alunos provenientes do ensino público ou do ensino privado na condição de bolsista integral" (VELOSO; MACIEL, 2015, p. 232).

Neste mesmo período, as Instituições Federais de Ensino Superior - IFES, comprometeram-se, como forma de garantir o repasse de recursos, com o Ministério de Educação - MEC, por meio do Programa de Apoio a Planos de Reestruturação e Expansão 
das Universidades Federais - REUNI, uma das ações integrantes do Plano de Desenvolvimento da Educação - PDE (2001-2010), a cumprir determinadas metas relativas a ampliar a oferta de Educação Superior, aumentando as taxas de conclusão dos cursos de graduação, ampliando as vagas especialmente nos cursos noturnos, reduzir a taxa de evasão e diminuir as vagas ociosas (VELOSO; NOGUEIRA; LUZ, 2014).

De acordo com o Censo da Educação Superior (2016), em 2002, no Brasil havia 1.637 IES, sendo 195 públicas e 1.442 privadas; já em 2016, o número total de IES tem um aumento de 47\%, passando para 2.407; dentre estas, 296 IES são públicas e 2.111 IES são privadas. Em 2002 as IES públicas possuíam 1.085.977 alunos matriculados em cursos presenciais e as IES privadas 2.434.650, em 2016 o número de alunos matriculados nos cursos presenciais de instituições públicas aumenta 82,5\% atingindo o total de 1.990.078. Destacam-se também as diferenças regionais apontadas por Araújo: em 2013, 48\% das IES estavam no sudeste, bem como $47 \%$ das IES públicas do país. "A territorialidade é um aspecto destacado nas políticas expansionistas, considerando uma intensa concentração nas IES e da oferta de vagas em determinadas regiões geográficas do país.” (2016, p.99).

Maciel, Lima e Gimenez (2016, p. 763) ressaltam que "o acesso à Educação Superior é limitado por diversos fatores, como a desigualdade social, a renda familiar, a cor/etnia, os fatores socioeconômicos e culturais". Neste sentido, ampliar tão somente o número de oferta de vagas nas IES, como forma de democratização deste nível de ensino, sem pensar nos fatores que interferem diretamente na conclusão ou não dos cursos de graduação, resolve o problema do ingresso, mas acaba por evidenciar um novo problema, a evasão estudantil nas IES.

O ingresso se concretiza; no entanto, o número elevado de estudantes que não permanecem nos cursos até sua conclusão torna-se um desafio para todas as IES. Gilioli (2016, p. 48) destaca que "a evasão nos cursos de graduação em instituições de ensino superior é um desafio em qualquer país", isto é, esse problema nos últimos anos tem afetado todas as IES do Brasil e fora dele, sejam elas públicas ou privadas, este fenômeno também ocorre em outros níveis e modalidades de ensino.

Com base no exposto, podemos constatar que, em relação à Educação Superior tem-se buscado, por meio de políticas públicas, quebrar o estigma de ter nascido para atender demandas da elite. O estudo aqui apresentado toma como um exemplo dessas políticas de democratização da Educação Superior, a implantação e expansão da Universidade do Estado de Mato Grosso - UNEMAT no interior do Estado de Mato Grosso, que será abordado a seguir.

\section{A UNEMAT no contexto da interiorização da Educação Superior}

Em meio ao processo de divisão do estado em dois - Mato Grosso e Mato Grosso do Sul, foi criado o Instituto de Ensino Superior de Cáceres, entidade autárquica municipal, que futuramente se tornaria Universidade do Estado de Mato Grosso - UNEMAT.

A UNEMAT surge da necessidade de se obter mão de obra qualificada para atuar nas escolas locais (RIEDER, 2011). O primeiro passo para resolução do problema, segundo Rieder, foi a constituição de uma comissão para traçar o projeto de Educação Superior em Cáceres, tendo surgido então, o Instituto de Ensino Superior de Cáceres IESC, que se transformou em Universidade do Estado de Mato Grosso - UNEMAT, em 1993, por meio da Lei Estadual n 030.

Segundo Rieder (2011), os primeiros cursos ofertados na IES, foram os cursos de licenciatura em Letras, Estudos Sociais e Ciências, que tiveram a aula inaugural realizada 
em setembro de 1978; anos mais tarde a IES passou a ofertar também cursos de bacharelado.

Ao constatar a fragilidade e a possibilidade de extinção da IES, o dirigente da instituição, na ocasião, buscou por maior estabilidade e suporte político, constatando que a necessidade de cursos de formação em nível superior era de todo o interior do estado.

Este acabou sendo um passo para a interiorização da Educação Superior no estado, iniciado por meio do I Seminário de Expansão do Ensino Superior Estadual, no qual foram realizadas as discussões para a instalação dos primeiros núcleos, que posteriormente se tornariam campus, implantados entre os anos de 1992 e 1995.

A criação do Núcleo de Ensino Superior de Sinop se deu por meio do Decreto Estadual $n^{\circ}$ 2.720/1990 e posteriormente tornou-se Campus Universitário de Sinop, foi antes da realização do seminário, do qual resultou a criação dos Núcleos de Ensino Superior de Alta Floresta, Alto Araguaia, Luciara, Nova Xavantina, Pontes e Lacerda, Barra do Bugres, Colíder e Tangará da Serra, criados entre os anos de 1992 e 1995. Tal como o Núcleo de Sinop, todos tornaram-se Campus Universitários (UNEMAT, 2018).

De acordo com Gianesini (2009, p. 71) "a expansão para o interior ocorreu num período de transformações econômicas e socioculturais, provocadas pelo desenvolvimento agrícola e pelo segundo momento do processo migratório", para o "nortão" do estado, região onde se situam Sinop, Alta Floresta e Colíder.

De acordo com Anuário Estatístico (2018), a UNEMAT conta com 13 Campus, 24 Faculdades, 17 Núcleos Pedagógicos, 24 Pólos Educacionais e está presente em 42 cidades (Figura 1). Destes, os núcleos são temporários, isto é, "aumenta[m] ou diminui[em] de acordo com os cursos que se iniciam ou se concluem" (LIMA; MALANGE; BARBOSA, 2018, p. 226). A cada curso encerrado, o núcleo pedagógico ao qual ele estiver vinculado é extinto e, a partir do momento em que se cria um novo curso, esse núcleo é reativado.

Além dos cursos de graduação, a instituição oferta também 26 cursos de Pósgraduação Stricto Sensu, sendo 19 mestrados dos quais 11 são acadêmicos e oito profissionais em rede; sete doutorados, quatro acadêmicos e três em rede; e oito especializações Lato Sensu ofertadas na modalidade a distância.

De acordo com o Anuário Estatístico (2018), a UNEMAT ofertou, na modalidade de oferta contínua (presencial), o total de 26 cursos, sendo 07 (27\%) licenciatura plena e 19 (73\%) cursos de bacharelado. Aparentemente pode parecer pouca essa quantidade, contudo ao se efetuar a contabilização dos cursos nos 13 campus ofertantes, atingimos a totalidade de 67 cursos presenciais de oferta contínua.

Paralelamente à expansão dos campus pelo interior do estado, ocorreu a implantação dos cursos na modalidade diferenciada, iniciando pelo Projeto de Licenciaturas Plenas Parceladas, seguido da Faculdade Indígena, cursos que se enquadram na modalidade diferenciada ofertados pela IES e por fim, os cursos a distância.

A partir de 2001 a IES passou a ofertar também cursos na modalidade a distância, na ocasião disponibilizou os cursos de Licenciatura em Pedagogia e Educação Infantil. A implantação desta modalidade foi incorporada à filosofia inicial da UNEMAT - formação de professores para atuarem na rede pública de ensino (Educação Básica e Ensino Médio). Nove anos depois da implantação da Educação a Distância, a UNEMAT passa a fazer parte do Sistema Universidade Aberta do Brasil - UAB, passando a oferecer cursos de graduação e pós-graduações a toda comunidade. Em 2018 UNEMAT/UAB ofertou quatro cursos de bacharelado e nove cursos de licenciaturas. 
Desta forma a UNEMAT se faz presente em praticamente todo Estado, conforme podemos visualizar na Figura 1 adiante, na qual destacamos os campus universitários como também os polos educacionais e os núcleos pedagógicos.

Figura 1 - Munícipios de atuação da UNEMAT

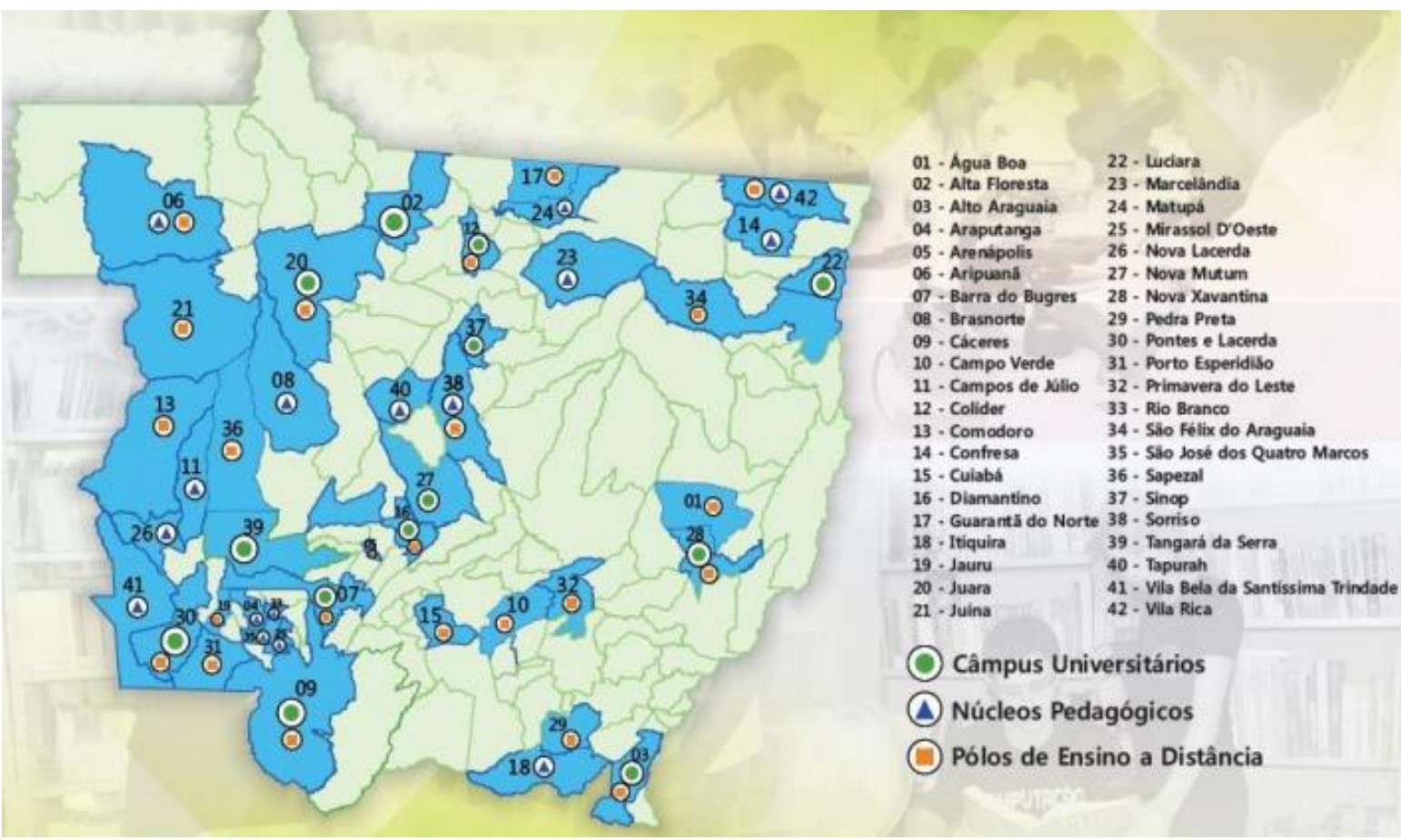

Fonte: UNEMAT - Pró-reitoria de Planejamento e Tecnologia da Informação/PRPTI - PDI 2017-2021 (p.

A UNEMAT oferta Educação Superior pública e gratuita, oportunizando assim, aos que não têm como se deslocar para os grandes centros, cursar uma graduação ou pósgraduação perto de casa.

A expansão da IES corporificou-se, no ano de 2018, ofertando 189 cursos (licenciaturas e bacharelados) entre as modalidades de oferta contínua e modalidades diferenciadas, com o total de 21.358 estudantes matriculados (UNEMAT, 2018). Ainda que tenha-se constatado o crescimento da IES, o fato não exime os cursos por ela ofertado da evasão.

\section{Cursos de licenciatura na UNEMAT/Campus Cáceres}

Apresentamos, a seguir, dados referentes à situação acadêmica de estudantes ingressantes em 2014/1 nos seis cursos de licenciatura da UNEMAT/Cáceres, finalizados no ano de 2017, considerando que o tempo mínimo para integralização dos cursos é de quatro anos conforme seus PPCs.

Quadro 1 - Situação acadêmica dos estudantes dos cursos de licenciatura do Campus Cáceres em 2017/2

\begin{tabular}{|c|c|c|c|c|c|c|}
\hline \multirow{2}{*}{ Cursos } & Ingressantes & \multicolumn{5}{|c|}{ Movimentação Acadêmica } \\
\cline { 5 - 7 } & $\mathbf{2 0 1 4 / 1}-\mathbf{S i S U}$ & $\begin{array}{c}\text { Formados } \\
\mathbf{2 0 1 7 / 2}\end{array}$ & $\begin{array}{c}\text { Retidos } \\
\mathbf{2 0 1 7 / 2}\end{array}$ & $\begin{array}{c}\text { Evadidos } \\
\mathbf{2 0 1 7 / 2}\end{array}$ & $\begin{array}{c}\text { Trancados } \\
\mathbf{2 0 1 7 / 2}\end{array}$ & $\begin{array}{c}\text { Transferidos } \\
\mathbf{2 0 1 7 / 2}\end{array}$ \\
\hline Pedagogia & $\begin{array}{c}37 \\
(100 \%)\end{array}$ & $\begin{array}{c}14 \\
(38 \%)\end{array}$ & $\begin{array}{c}8 \\
(21 \%)\end{array}$ & $\begin{array}{c}15 \\
(41 \%)\end{array}$ & 0 & 0 \\
\hline
\end{tabular}




\begin{tabular}{|c|c|c|c|c|c|c|}
\hline Letras & $\begin{array}{c}39 \\
(100 \%)\end{array}$ & $\begin{array}{c}9 \\
(23,5 \%)\end{array}$ & $\begin{array}{c}8 \\
(20,5 \%)\end{array}$ & $\begin{array}{c}18 \\
(46,5 \%)\end{array}$ & $\begin{array}{c}4 \\
(10,5 \%)\end{array}$ & 0 \\
\hline Matemática & $\begin{array}{c}40 \\
(100 \%)\end{array}$ & $\begin{array}{c}2 \\
(5 \%)\end{array}$ & $\begin{array}{c}9 \\
(22,5 \%)\end{array}$ & $\begin{array}{c}25 \\
(62,5 \%)\end{array}$ & $\begin{array}{c}3 \\
(7,5 \%)\end{array}$ & $\begin{array}{c}1 \\
(2,5 \%)\end{array}$ \\
\hline História & $\begin{array}{c}40 \\
(100 \%)\end{array}$ & $\begin{array}{c}3 \\
(7,5 \%)\end{array}$ & $\begin{array}{c}7 \\
(17,5 \%)\end{array}$ & $\begin{array}{c}26 \\
(65 \%)\end{array}$ & $\begin{array}{c}3 \\
(7,5 \%)\end{array}$ & $\begin{array}{c}1 \\
(2,5 \%)\end{array}$ \\
\hline Geografia & $\begin{array}{c}40 \\
(100 \%)\end{array}$ & $\begin{array}{c}7 \\
(17,5 \%)\end{array}$ & $\begin{array}{c}17 \\
(42,5 \%)\end{array}$ & $\begin{array}{c}12 \\
(30 \%)\end{array}$ & $\begin{array}{c}4 \\
(10 \%)\end{array}$ & 0 \\
\hline Educação Física & $\begin{array}{c}40 \\
(100 \%)\end{array}$ & $\begin{array}{c}10 \\
(25 \%)\end{array}$ & $\begin{array}{c}10 \\
(25 \%)\end{array}$ & $\begin{array}{c}16 \\
(40 \%)\end{array}$ & $\begin{array}{c}3 \\
(7,5 \%)\end{array}$ & $\begin{array}{c}1 \\
(2,5 \%)\end{array}$ \\
\hline TOTAL & $\begin{array}{c}236 \\
(100 \%)\end{array}$ & $\begin{array}{c}45 \\
(19 \%)\end{array}$ & $\begin{array}{c}59 \\
(25 \%)\end{array}$ & $\begin{array}{c}112 \\
(47 \%)\end{array}$ & $\begin{array}{c}17 \\
(7,5 \%)\end{array}$ & $\begin{array}{c}3 \\
(1,5 \%)\end{array}$ \\
\hline
\end{tabular}

Fonte: Produzido pelos autores, com dados do Sistema SAGU 2018/1.

Ao verificar as condições de vínculo (conclusão, retenção, desistência, transferência e trancamento) ao final do período 2017/2, nas quais os estudantes podem estar situados, conforme o seu percurso acadêmico, de acordo com dados expostos no Quadro 1, identificamos os seguintes números: 47\% (112) de desistência, 25\% (59) retidos, 19\% (45) formados, 7,5\% (17) trancados e 1,5\% (3) transferidos.

Entendemos o conceito de evasão como "situação de não continuidade do percurso acadêmico dos estudantes, evidenciada pela não matrícula no curso de ingresso, em outro curso da mesma ou outra IES" (LIMA; MALANGE; BARBOSA, 2018, p. 3), ou seja, é possível tratar de evasão em nível de curso ou de instituição. No entanto, dados os objetivos deste trabalho, nos pautamos na evasão de curso. Isto é, no "desligamento do curso superior em razão do abandono/desistência, que ocorre pela não realização da matrícula ou pela exclusão por desatendimento a alguma norma institucional" (LIMA; MALANGE; BARBOSA, 2018, p. 3), o que implica em não considerar transferências, trancamentos e/ou retenções como evasão.

Sob esta perspectiva, dos 236 estudantes ingressantes em 2014/1 ao final do período mínimo de integralização do curso, ou seja, em 2017/2, 47\% havia evadido, sendo que os cursos de História e de Matemática apresentam maior quantidade de evasão por curso, acima de 50\%. Pedagogia e Letras apresentam os menores números, abaixo de $19 \%$.

Segundo Indicadores Educacionais do Instituto Nacional de Estudos e Pesquisas Educacionais Anísio Teixeira - INEP, apresentados em maio/2018, por membros da Diretoria Estatística do INEP, no Simpósio sobre indicadores de Fluxo de Estudantes na Educação Superior na Universidade Estadual de Campinas - UNICAMP, a trajetória acadêmica dos estudantes ingressantes em 2010 é interrompida em mais de $50 \%$ em decorrência de mudança de turma/instituição ou desistência do curso; apenas 34\% concluiu a graduação e 10\% permanece no curso" (BRASIL, 2017).

Ao efetuar a divisão temporal dos cursos em anos letivos, ou seja, quatro anos, tempo mínimo estipulado nos PPCs dos cursos para sua integralização, observando o fluxo dos estudantes em relação à desistência, atingimos os resultados expostos no Gráfico 2, a saber: 
Gráfico 2 - Quantidade de desistência dos estudantes dos cursos de licenciatura da UNEMAT/Cáceres por ano letivo.

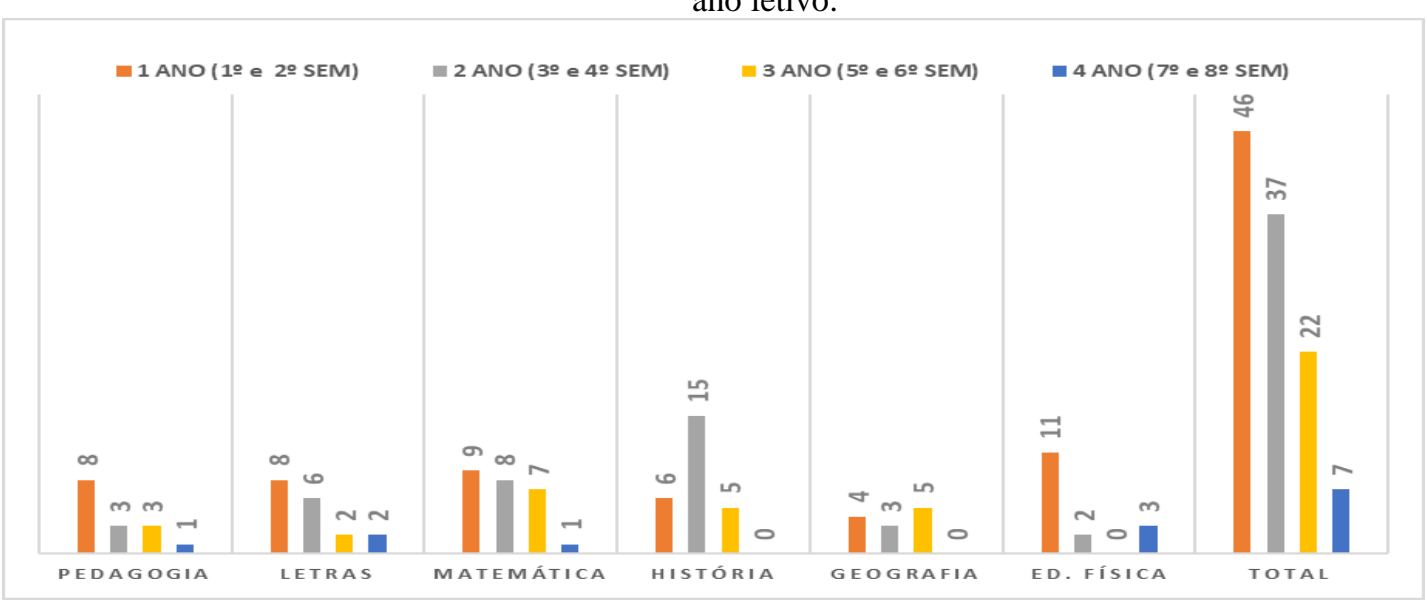

Fonte: Elaborado pelos autores com base nos dados do Sistema SAGU (2018).

De maneira geral dos 112 estudantes que interromperam sua trajetória acadêmica no decorrer do período de 2014/1 a 2017/2, 41\% (46) desistiu de seu curso no primeiro ano letivo (2014); entre o primeiro e o segundo semestres, 33\% (37); no segundo ano (2015), $20 \%$ (22); no terceiro ano (2016) e $6 \%$ (7) no quarto ano (2017).

No geral observa-se uma tendência de diminuição da quantidade de evadidos na medida em que se avança em direção ao final do curso. Havendo uma proporção de quase três vezes mais desistências na primeira metade do curso do que na parte final.

Dos estudantes que desistiram no primeiro ano, a grande maioria são dos cursos de Pedagogia (8), Letras (8), Matemática (9) e Educação Física (11). No segundo ano a maioria dos desistentes foram do curso de História (15) e no terceiro ano do curso de Geografia (5).

Para Rigo (2016), o abandono e/ou fracasso no primeiro ano da Educação Superior está associado ao momento de transição do ensino médio para a Educação Superior, devido ao fato de o indivíduo estar conhecendo um novo mundo, novas regras, bem como os saberes desse novo espaço, que devem ser incorporados por esse estudante, caso contrário, ele não se sentirá integrado.

Coulon (2017, p. 1241) afirma em estudo realizado junto a estudantes franceses que "é durante o primeiro ano que as coisas são mais difíceis", segundo o autor, isso decorre do acesso das classes populares à Educação Superior, nível de ensino este, até então elitistas. Por outro lado, os estudantes nem sempre têm o nível requisitado e, ao contrário, têm certos hábitos culturais e sociais que não lhes facilitam a entrada nesse meio universitário.

Tendo alcançado grande parte dos propósitos expansionistas e democráticos do ingresso dos estudantes aos cursos de graduação nas IES de todo o país, bem como na UNEMAT, a Universidade depara-se atualmente com a preocupação da permanência dos estudantes na instituição até a conclusão do curso.

A análise dos indicadores de ingressantes e de formados indica que a permanência nos cursos precisa ser compreendida para além dos dados quantitativos como o fator motivacional destacado por Neves (2019, p. 134) “a busca pela profissionalização e consequentemente pela ascensão profissional, segundo os estudantes concluintes é um fator motivador para a permanência e conclusão do curso". Podemos supor que além desse, há outros fatores que estão interferindo na trajetória acadêmica dos que ingressam nesse 
nível de ensino, o que pode estar contribuindo para a não conclusão do curso ou para a prorrogação de seu tempo de conclusão da graduação, a retenção.

\section{CONSIDERAÇÕES FINAIS}

Neste trabalho apresentou-se de forma resumida a trajetória da Universidade do Estado de Mato Grosso - UNEMAT no contexto da expansão da Educação Superior no Brasil. Tais como as outras IES no país, mesmo considerando as conquistas advindas do processo de democratização a UNEMAT também se depara com problemas relativos à evasão e permanência.

O estudo estendeu-se à interiorização da UNEMAT que, por sua vez, acompanhou o processo de expansão e democratização do acesso das IES nacionais, porém de maneira diferenciada, por ter nascido com o propósito de suprir a deficiência de professores nas escolas cacerenses e, posteriormente, nas escolas de todo o estado, tornando-se assim, uma universidade "do interior para o interior".

Os dados dos seis cursos analisados indicam que a evasão nestas licenciaturas, na série histórica estudada (2014-2017) ficou entre 30\% e 65\%, no tempo mínimo previsto nos PPCs para integralização, ou seja, a evasão se faz presente desde os primeiros semestres, o que indica uma necessidade de políticas de permanência com foco no acompanhamento da trajetória acadêmica dos estudantes.

Muitos dos propósitos expansionistas e democráticos de ingresso dos estudantes nos cursos de graduação nas IES de todo o país foram alcançados, bem como na UNEMAT, contudo os programas destinados a favorecer a permanência na Educação Superior, ainda não foram suficientes para vencer o desafio da evasão.

Consideramos que o foco das políticas e ações para o sucesso escolar, ou seja, a conclusão dos cursos de graduação com qualidade deve considerar o ingresso dos estudantes indissociável da sua permanência nos cursos. A separação de estratégias específicas para cada problema demonstra a falta de políticas que fortaleçam o acesso do estudante à Educação Superior e a sua permanência até concluir os cursos.

\section{REFERÊNCIAS}

ARAÚJO, Rhoberta Santana de. Expansão do Ensino Superior e desenvolvimentismo: limites e contradições sob a hegemonia do capital. Educação e Fronteiras On-Line, Dourados/MS, v.6, n.16 p.93-105, jan./abr. 2016.

BRASIL. Ministério de Educação - MEC. O PNE 2011-2020: metas e estratégias. Brasília: MEC, 2010. Disponível em:

<http://fne.mec.gov.br/images/pdf/notas_tecnicas_pne_2011_2020.pdf >. Acesso em: 20 de jul. 2017.

. Ministério de Educação - MEC. A democratização e expansão da Educação

Superior no País 2003-2014. Disponível em:

$<$ http://portal.mec.gov.br/index.php?option=com_docman\&view=download $\&$ alias $=16762-$ balanco-social-sesu-2003-2014\&Itemid=30192 >. Acesso em: 20 de jul. 2017.

. Lei no 13.005, de 25 de Junho de 2014. Aprova o Plano Nacional de Educação PNE e dá outras providências. Disponível em: 
<http://www.planalto.gov.br/ccivil_03/_Ato2011-2014/2014/Lei/L13005.htm>. Acesso em: 20 de jul. 2017.

Ministério de Educação - MEC. Censo da Educação Superior 2016.

Disponível em: http://portal.mec.gov.br/ultimas-noticias/212-educacao-superior1690610854/40111-altos-indices-de-evasao-na-graduacao-revelam-fragilidade-do-ensinomedio-avalia-ministro. Acesso em: 20 de jul. 2017.

MEC/INEP. Instituto Nacional de Estudos e Pesquisas Educacionais Anísio Teixeira. Indicadores educacionais. Brasília-DF, 2017. Disponível em: <http://portal.inep.gov.br/indicadores-educacionais>. Acesso em: 8 de nov. 2018.

COULON, Alain. O ofício de estudante: a entrada na vida universitária. Texto tradução da Prof ${ }^{a}$. Dr ${ }^{\mathrm{a}}$. Ana Maria F. Teixeira da Universidade Federal do Recôncavo da Bahia UFRB. Disponível em: < http://www.scielo.br/pdf/ep/v43n4/1517-9702-ep-43-41239.pdf>. Acesso em: 10 ago. 2017

GIANEZINI, Quelen. O processo de expansão do Ensino Superior em Mato Grosso. 2009. 238 f. Dissertação (Mestrado em Sociologia) - Universidade Federal do Rio Grande do Sul/UFRGS. Porto Alegre/RS, 2009.

GILIOLI, Renato de Souza Porto. Evasão em Instituições Federais de Ensino Superior no Brasil: expansão da rede, SISU e desafios. Brasília: Consultoria Legislativa. Estudo Técnico Maio/2016.

LIMA, Elizeth Gonzaga dos Santos; MALANGE, Fernando Cezar Vieira; BARBOSA. Valci Aparecida. Políticas de Expansão da Educação Superior Implantadas pelo Estado Brasileiro: reflexões sobre democratização. IN: CHAVES, Vera Lucia Jacob; MAUÉS, Oldaíses Cabral; HAGE, Salomão Mufarrej (Org.). Expansão privado-mercantil da Educação Superior no Brasil. Campinas, SP: Mercado de Letras, 2018.

MACIEL, Carina Elisabeth; LIMA, Elizabeth Gonzaga dos Santos; GIMENEZ, Felipe Vieira. Políticas e permanência para estudantes na Educação Superior. RBPAE, v. 32, n. 3, p. 759-781, set./dez. 2016.

NEVES, Suzely Paesano. Permanência na Educação Superior: uma análise do percurso acadêmico dos estudantes de licenciatura da Universidade do Estado de Mato Grosso Câmpus Jane Vanini. Dissertação (Mestrado em Educação). Programa de Pós-Graduação em Educação da UNEMAT - Universidade do Estado de Mato Grosso, Cáceres, 2019.

RIEDER, Arno. A interiorização da Educação Superior no Brasil: caso de Mato Grosso. Rev. Gual., Florianópolis, v.4, n. 3, p. 228-247, set/dez. 2011.

RIGO, Júlia da Silva. Percursos de formação de estudantes de licenciatura noturna na UFV: ENEM, SISU e evasão. 2016. 135 f. Dissertação (Mestrado em Educação) Universidade Federal de Viçosa/UFV, Minas Gerais/MG, 2016. 
UNEMAT. Anuário Estatístico UNEMAT 2018 ano base 2017. Disponível em: http://portal.unemat.br/media/files/PRPTI/ANUARIO-2018-ANO-BASE-2017.pdf. Acesso em: 02 dez. 2018.

VASCONCELOS. Ana Maria Nogales. Juventude e Ensino Superior no Brasil. In: Jovens Universitários em um Mundo em Transformação: uma pesquisa sino-brasileira. p. 125-137. Disponível em:

http://repositorio.ipea.gov.br/bitstream/11058/9062/1/Juventude\%20e\%20ensino.pdf. Acesso em 16 nov. 2019.

VELOSO, Tereza Christina Mertens Aguiar; NOGUEIRA, Patrícia Simone; LUZ, Jackeline Nascimento Noronha da. Políticas públicas de acesso na Educação Superior: uma análise a partir dos indicadores da realidade. In: Anais do XXII Seminário Nacional Universitas/Br. Natal/RN, 21 a 23 de maio 2014.

VELOSO, Tereza Christina Mertens Aguiar; MACIEL, Carina Elisabeth. Acesso e permanência na Educação Superior - análise da legislação e indicadores educacionais. Revista Educação em Questão. Natal, v. 51, n. 37, p. 224-250, jan/abr 2015. 